\title{
The use of multivariate analysis to characterize carcass and meat quality of goat kids protected by the PGI "Cabrito de Barroso"
}

\author{
V.A.C. Santos*, J.A. Silva, A.M.D. Silvestre, S.R. Silva, J.M.T. Azevedo \\ CECAV - University of Trás-os-Montes and Alto Douro, Apartado 1013, 5001-801 Vila Real, Portugal
}

Received 20 November 2006; received in revised form 15 June 2007; accepted 22 August 2007

\begin{abstract}
Fifty five suckling kids from three genotypes and two sexes protected by the PGI "Cabrito de Barroso" European quality label were used in this experiment. Carcass quality was assessed using indices from carcass measurements, dressing percentages, refrigerated losses, higher priced joints proportion and tissue composition of the carcass. Meat $\mathrm{pH}$, colour, total pigment, fat, dry matter, collagen determinations (total and soluble), cooking losses and shear force estimated in longissimus thoracis et lumborum (LTL) and gluteobiceps (GB) muscles were used to characterize meat quality. Principal component (PC) analysis was performed in order to examine carcass quality traits $(n=16)$ and meat quality $(n=16)$ traits. The five first principal components (PCs) explained about $86 \%$ of the total variability for carcass quality and $75 \%$ of the total variability for meat quality. Compactness indices of carcass and leg, carcass weight and subcutaneous fat were the most effective variables for the PC1, whereas the higher priced joints proportion, muscle proportions of the higher priced joints and of the carcass and the muscle and bone ratio were useful to define the PC2. The first PC of the meat quality parameters was characterized by colour traits ( $L^{*}, b^{*}, a^{*}, C^{*}, H^{*}$ and total pigment) whereas collagen determinations (total collagen and collagen solubility) defined the second PC. When the carcass quality data were projected on the plane defined by the first two PCs, two separate groups of points appeared, corresponding to the animals with slaughter live weight higher or lower than $10 \mathrm{~kg}$. The distribution of the meat quality data on the plane defined by the first two PCs allowed the identification of two separate groups, corresponding to the muscles GB and LTL. The differences between genotypes tend to be small and related to slaughter live weight, which implies certain constancy in carcass and meat quality of the PGI "Cabrito de Barroso".
\end{abstract}

(C) 2007 Elsevier B.V. All rights reserved.

Keywords: Goat kids; Principal component analysis; Carcass; Meat quality

\section{Introduction}

Carcass characteristics and meat quality of goats can be affected by genotype (Dhanda et al., 1999a,b; Oman et al., 2000), sex (Hogg et al., 1992; Todaro et al., 2004),

\footnotetext{
* Corresponding author. Tel.: +351 259350430; fax: +351 259350482.

E-mail address: vsantos@utad.pt (V.A.C. Santos).
}

diet and production system (Johnson and McGowan, 1998; Marinova et al., 2001) and weight at slaughter (Marichal et al., 2003). Nevertheless other factors could influence meat quality such as pre-slaughter treatment, carcass chilling, muscle type or ageing time (Kadim et al., 2003; Webb et al., 2005). European meat quality labels, such as "Cabrito de Barroso"-PGI, have a recognized value that should be validated by scientific studies. "Cabrito de Barroso"-PGI is produced in the "Barroso" region (North of Portugal) by a traditional method but 
Table 1

Mean, standard deviation (SD) and coefficient of variation (CV) of the carcass quality measurements

\begin{tabular}{lrrc}
\hline Variables & Mean & SD & CV (\%) \\
\hline Hot carcass weight (HCW), kg & 5.08 & 1.10 & 21.7 \\
Dressing percentage (DP1), \% & 50.49 & 2.53 & 5.0 \\
Dressing percentage2 (DP2), \% & 56.10 & 2.14 & 3.8 \\
Refrigerated losses (RL), \% & 5.45 & 2.42 & 44.3 \\
Carcass compactness index (CC) & 0.11 & 0.02 & 16.7 \\
Buttock/leg index (B/Lg) & 0.56 & 0.07 & 11.8 \\
Chest roundness index (ChR) & 0.60 & 0.06 & 10.4 \\
Leg compactness index (LgC) & 22.89 & 3.89 & 17.0 \\
Higher priced joints (HPJ), \% & 43.92 & 1.17 & 2.7 \\
Muscle higher priced joints (MHPJ), \% & 47.23 & 1.16 & 2.5 \\
Muscle (M), \% & 64.81 & 2.71 & 4.2 \\
Subcutaneous fat (SF), \% & 4.07 & 1.15 & 28.4 \\
Intermuscular fat (InterF), \% & 8.75 & 2.55 & 29.2 \\
Bone (B), \% & 20.96 & 1.36 & 6.5 \\
Muscle:bone ratio (M:B) & 3.10 & 0.22 & 7.1 \\
Subcutaneous:muscle ratio (SF:M) & 0.06 & 0.02 & 31.4 \\
\hline
\end{tabular}

Dressing percentage1 (SLW basis).

Dressing percentage2 (ELW basis).

following precise specifications. Carcasses from this PGI must weight from 4 to $6 \mathrm{~kg}$, be obtained from male and female kids up to three months of age, raised on pasture with their mothers in the Barroso highlands, and belonging to the local Serrana (S) and Bravia (B) goat breeds or their crossbreeds $(\mathrm{S} \times \mathrm{B})$. Studies on goats to characterize carcass quality have mostly focused on carcass evaluation, with objective or subjective measurements, and tissue carcass distribution (Oman et al., 2000; Cameron et al., 2001; Marinova et al., 2001; Marichal et al., 2003; Sen et al., 2004; Kadim et al., 2003) at a fixed slaughter live weight or at variable slaughter live weight. Studies on goat meat quality are usually based on $\mathrm{pH}$, objective tenderness and colour measurements, chemical composition and sensorial analysis (Marinova et al., 2001; Sen et al., 2004; Kadim et al., 2003) and more recently on muscle fibre population (Marichal et al., 2003). To assess carcass and meat quality several related traits are considered. Karlsson (1992) proposed the use of principal component (PC) analysis for evaluating meat quality when several correlated measurements are used. This multivariate statistical technique is used to find a smaller set of measurements explaining most of the observed variability in the measurements taken, but also helps in examining the relationships between traits and the differences between the groups of animals compared (Hernández et al., 2000). PC analysis has been used before to describe carcass characteristics (Laville et al., 1996; Hernández et al., 2000; Cañeque et al., 2004) and meat quality (Karlsson, 1992; Næs et al., 1996; Hernández et al., 1997; Hernández et al., 1998, 2000; Destefanis et al., 2000; Albertí et al., 2005; Cañeque et al., 2004) of several species and seems to be a very useful tool to visualize and interpret the data. Furthermore, other multivariate statistical methodologies, such as discriminant analysis (DA) can also be suitable (Moreno et al., 2006; Oliete et al., 2006). Discriminant analysis is a supervised classification tool used to differentiate groups of samples as a function of one of several combinations of experimental variables (Brito et al., 2006). The objective of this paper is to analyse carcass and meat quality of goat kids protected by the PGI "Cabrito de Barroso" applying multivariate analysis.

\section{Material and methods}

Animal handling followed the EU directive number 86/ 609/EEC concerning animal care.

\subsection{Animals}

Data on fifty five suckling kids (28 males and 27 females) of three genotypes $(18 \mathrm{~B}, 19 \mathrm{~S}$ and 18 crossbred $\mathrm{S} \times \mathrm{B}$ ) slaughtered at a range of live weight between 7 and $13 \mathrm{~kg}(21-$ $27 \%$ of mature live weight) were analysed. The kids came from several farms and were produced according to "Cabrito de Barroso-PGI" specifications. The selection of kids was done regardless of birth type. When very young, the kids were penned at the farm during the first two weeks, while their dams spent the day at pasture. After this period, kids were naturally suckled and left to graze with their dams.

\subsection{Carcass characteristics}

The slaughter and carcass dressing were performed following the methods of Colomer-Rocher et al. (1987).

Table 2

Mean, standard deviation (SD) and coefficient of variation (CV) of the meat quality measurements

\begin{tabular}{lrlr}
\hline Variables & Mean & SD & CV $(\%)$ \\
\hline pH1 & 6.54 & 0.24 & 3.7 \\
pH24 & 5.76 & 0.19 & 3.3 \\
T1 $\left({ }^{\circ} \mathrm{C}\right)$ & 25.94 & 3.65 & 14.1 \\
T24 $\left({ }^{\circ} \mathrm{C}\right)$ & 4.98 & 1.13 & 22.7 \\
Lightness $\left(L^{*}\right)$ & 47.33 & 4.27 & 9.0 \\
Redness $\left(a^{*}\right)$ & 16.95 & 1.77 & 10.5 \\
Yellowness $\left(b^{*}\right)$ & 5.17 & 0.89 & 17.3 \\
Chromaticity $\left(C^{*}\right)$ & 17.84 & 1.61 & 9.0 \\
Hue $\left(H^{*}\right)$ & 18.89 & 4.72 & 25.0 \\
Dry matter (DM), \% & 23.60 & 0.71 & 3.0 \\
Intramuscular fat (IntraF), \%DM & 4.41 & 2.12 & 48.1 \\
Cooking loss (CL), \% & 11.13 & 3.04 & 27.4 \\
Shear force (SF), kg/cm ${ }^{2}$ & 7.74 & 2.32 & 29.9 \\
Total pigment (Pigm), mg/g & 1.13 & 0.39 & 34.6 \\
Collagen solubility $(\mathrm{CS}), \%$ total & 7.77 & 2.22 & 28.6 \\
Total collagen (TC), \%DM & 2.78 & 0.87 & 31.4 \\
\hline
\end{tabular}


Table 3

Correlations coefficients $(r)$ between the carcass quality measurements

\begin{tabular}{|c|c|c|c|c|c|c|c|c|c|c|c|c|c|c|c|}
\hline & $\mathrm{HCW}$ & DP1 & DP2 & $\mathrm{CL}$ & $\mathrm{CC}$ & $\mathrm{B} / \mathrm{Lg}$ & ChR & $\mathrm{LgC}$ & HPJ & MHPJ & M & SF & InterF & B & M:B \\
\hline DP1 & 0.50 & & & & & & & & & & & & & & \\
\hline DP2 & 0.49 & 0.85 & & & & & & & & & & & & & \\
\hline CL & -0.53 & -0.42 & -0.41 & & & & & & & & & & & & \\
\hline $\mathrm{CC}$ & 0.96 & 0.53 & 0.54 & -0.56 & & & & & & & & & & & \\
\hline $\mathrm{B} / \mathrm{Lg}$ & 0.13 & 0.16 & 0.20 & -0.05 & 0.23 & & & & & & & & & & \\
\hline ChR & -0.14 & -0.16 & -0.08 & 0.41 & -0.09 & 0.41 & & & & & & & & & \\
\hline $\mathrm{LgC}$ & 0.93 & 0.47 & 0.53 & -0.46 & 0.93 & 0.33 & 0.02 & & & & & & & & \\
\hline HPJ & -0.10 & -0.05 & 0.07 & 0.07 & -0.02 & 0.33 & 0.25 & 0.09 & & & & & & & \\
\hline MHPJ & -0.08 & -0.01 & 0.05 & 0.04 & 0.00 & 0.24 & 0.18 & 0.09 & 0.86 & & & & & & \\
\hline M & -0.12 & -0.14 & 0.00 & 0.15 & -0.14 & 0.04 & 0.15 & -0.01 & 0.51 & 0.18 & & & & & \\
\hline SF & 0.40 & 0.34 & 0.31 & -0.18 & 0.46 & 0.35 & 0.13 & 0.43 & -0.10 & 0.22 & -0.67 & & & & \\
\hline InterF & 0.19 & 0.19 & 0.05 & -0.15 & 0.19 & -0.06 & -0.17 & 0.09 & -0.35 & 0.01 & -0.89 & 0.65 & & & \\
\hline B & -0.40 & -0.24 & -0.27 & 0.17 & -0.43 & -0.17 & -0.11 & -0.45 & -0.28 & -0.50 & 0.15 & -0.59 & -0.48 & & \\
\hline $\mathrm{M}: \mathrm{B}$ & 0.31 & 0.13 & 0.24 & -0.07 & 0.32 & 0.19 & 0.19 & 0.42 & 0.55 & 0.57 & 0.44 & 0.15 & -0.07 & -0.82 & \\
\hline SF:M & 0.38 & 0.32 & 0.27 & -0.18 & 0.44 & 0.31 & 0.10 & 0.39 & -0.15 & 0.18 & -0.74 & 0.99 & 0.71 & -0.56 & 0.08 \\
\hline
\end{tabular}

$\mathrm{HCW}$, hot carcass weight; DP1, dressing percentage1; DP2, dressing percentage2; RL, refrigerated losses; CC, carcass compactness index; B/Lg, buttock/leg index; ChR, chest roundness index; LgC, leg compactness index; HPJ, higher priced joints; MHPJ, muscle higher priced joints; M, muscle; SF, subcutaneous fat; InterF, intermuscular fat; B, bone; M:B, muscle:bone ratio; SF:M, subcutaneous:muscle ratio.

Carcasses were refrigerated for $24 \mathrm{~h}$ at $4{ }^{\circ} \mathrm{C}$. The hot and cold carcass weights (HCW and $\mathrm{CCW}$, respectively) were recorded and the refrigeration losses were calculated. The following carcass conformation measurements were taken: Carcass width (Wr: widest carcass measurement at the ribs), thoracic depth (Th: maximum distance between the sternum and the back of the carcass at the sixth thoracic vertebra), buttock width (G: widest buttock measurement in a horizontal plane on the hanging carcass), hind limb length ( $\mathrm{F}$ : length from perineum to distal edge of the tarsus) and internal carcass length ( $\mathrm{L}$ : length from cranial edge of the symphysis pelvis to the cranial edge of the first rib). The indices from these carcass conformation measurements: chest roundness index $(\mathrm{Wr} / \mathrm{Th})$, buttock/leg index $(\mathrm{G} / \mathrm{F})$, carcass compactness $(\mathrm{CCW} / \mathrm{L})$ and leg compactness (leg weight/F) were calculated (Fisher and de Boer, 1994; Velasco et al., 2000; Cañeque et al., 2004). The carcasses were split down the dorsal midline and the kidney knob and channel fat (KKCF) from the right-half carcass was weighed. The left side was joined into eight standardized commercial joints as outlined by Santos-Silva et al. (2002) for lamb carcasses. After weighing, each joint was separated into dissectible muscle, bone, fat (subcutaneous and intermuscular fat depots were registered separately) and the remainder (major blood vessels, ligaments, tendons and thick connective tissue sheets associated with some muscles) in a dissection room under controlled environment.

Table 4

Correlations coefficients $(r)$ between the meat quality measurements

\begin{tabular}{|c|c|c|c|c|c|c|c|c|c|c|c|c|c|c|c|}
\hline & $\mathrm{pH} 1$ & $\mathrm{pH} 24$ & $\mathrm{~T} 1$ & $\mathrm{~T} 24$ & $L^{*}$ & $a^{*}$ & $b^{*}$ & $C^{*}$ & $H^{*}$ & $\mathrm{DM}$ & IntraF & $\mathrm{CL}$ & $\mathrm{SF}$ & Pigm & $\mathrm{CS}$ \\
\hline $\mathrm{pH} 24$ & 0.34 & & & & & & & & & & & & & & \\
\hline $\mathrm{T} 1$ & -0.15 & 0.12 & & & & & & & & & & & & & \\
\hline T24 & -0.08 & -0.35 & 0.01 & & & & & & & & & & & & \\
\hline$L^{*}$ & -0.38 & -0.27 & 0.18 & 0.09 & & & & & & & & & & & \\
\hline$a^{*}$ & 0.37 & 0.16 & -0.20 & -0.06 & -0.88 & & & & & & & & & & \\
\hline$b^{*}$ & -0.06 & -0.08 & -0.11 & -0.01 & 0.68 & -0.44 & & & & & & & & & \\
\hline$C^{*}$ & 0.37 & 0.15 & -0.23 & -0.07 & -0.80 & 0.98 & -0.27 & & & & & & & & \\
\hline$H^{*}$ & -0.25 & -0.13 & 0.02 & -0.01 & 0.88 & -0.79 & 0.89 & -0.66 & & & & & & & \\
\hline $\mathrm{DM}$ & -0.05 & -0.21 & -0.18 & -0.11 & -0.12 & -0.01 & -0.07 & -0.02 & -0.02 & & & & & & \\
\hline IntraF & -0.03 & 0.21 & 0.28 & -0.30 & 0.19 & -0.11 & 0.24 & -0.07 & 0.23 & 0.20 & & & & & \\
\hline $\mathrm{CL}$ & -0.11 & -0.51 & -0.22 & 0.09 & 0.18 & -0.03 & 0.20 & 0.00 & 0.13 & 0.27 & 0.06 & & & & \\
\hline $\mathrm{SF}$ & 0.26 & -0.05 & 0.21 & -0.09 & 0.09 & -0.01 & 0.19 & 0.02 & 0.12 & -0.10 & 0.13 & 0.25 & & & \\
\hline Pigm & 0.28 & 0.30 & -0.13 & -0.11 & -0.85 & 0.80 & -0.55 & 0.75 & -0.74 & 0.11 & -0.03 & -0.15 & -0.10 & & \\
\hline $\mathrm{CS}$ & -0.12 & -0.21 & -0.23 & 0.18 & -0.01 & -0.08 & -0.14 & -0.11 & -0.07 & 0.12 & -0.24 & 0.09 & -0.17 & -0.11 & \\
\hline TC & 0.18 & 0.41 & 0.29 & -0.14 & 0.04 & 0.08 & 0.24 & 0.14 & 0.11 & -0.50 & 0.29 & -0.20 & 0.32 & 0.03 & -0.33 \\
\hline
\end{tabular}

$\mathrm{pH} 1, \mathrm{pH}$ measured at $1 \mathrm{~h}$ after slaughter; $\mathrm{pH} 24, \mathrm{pH}$ measured at $24 \mathrm{~h}$ after slaughter; T1, temperature measured $1 \mathrm{~h}$ after slaughter; T24, temperature measured $24 \mathrm{~h}$ after slaughter; $L^{*}, a^{*}, b^{*}$, chroma-meter values; $C^{*}$, chromaticity; $H^{*}$, hue; DM, dry matter; IntraF, Intramuscular fat; CL, cooking loss; SF, shear force; Pigm, total pigment; CS, collagen solubility; TC, total collagen. 
Table 5

Results from the principal component analysis for the first five principal components of the carcass quality measurements

\begin{tabular}{llll}
\hline Component & Eigenvalue & $\begin{array}{l}\text { Portion of variance } \\
(\%)\end{array}$ & $\begin{array}{l}\text { Cumulative variance } \\
(\%)\end{array}$ \\
\hline 1 & 5.55 & 34.7 & 34.7 \\
2 & 3.31 & 20.7 & 55.3 \\
3 & 2.52 & 15.7 & 71.1 \\
4 & 1.35 & 8.5 & 79.5 \\
5 & 1.08 & 6.7 & 86.3 \\
\hline
\end{tabular}

\subsection{Muscle sampling}

Samples of longissimus thoracis et lumborum (LTL) and gluteobiceps (GB) muscles were taken $24 \mathrm{~h}$ after slaughter, from the loin and leg, respectively, when carcass left halves were partitioned into commercial joints. Sub-samples of LTL were taken for colour and intramuscular fat (4th to final lumbar vertebra) analysis. Sub-samples of GB (medial portion) were taken for the same analyses. At the same time, carcass right LTL, between the 8th rib and 5th lumbar vertebra and the GB (total) muscles were excised and divided into three parts. One part of the muscle was vacuum packed and aged at $2 \pm 2{ }^{\circ} \mathrm{C}$ for 5 days post-mortem for cooking losses and tenderness objective determinations. After epimysium removal, the remaining portions were cut and frozen at $-18{ }^{\circ} \mathrm{C}$ until collagen and pigmentation determinations.

\subsection{Meat quality measurements}

The initial $\mathrm{pH}$ and temperature $(\mathrm{pH} 1$ and $\mathrm{T} 1)$ and ultimate $\mathrm{pH}$ and temperature (pH24 and T24) were evaluated at $1 \mathrm{~h}$ and $24 \mathrm{~h}$ after slaughter, respectively. These traits were measured directly in LTL (4/5th lumbar vertebra) and GB muscles (distal part) of the carcass' left side using a combined glass electrode with a pH-meter (Crison 2002). The colour was measured on LTL and GB muscles surface immediately after cutting at the same site as $\mathrm{pH}$. The meat colour was assessed using the $L^{*}$ (lightness) $a^{*}$ (redness) $b^{*}$ (yellowness) system by a chromo-meter (Minolta 310), which gives the average of three measurements. The colorimetric indices of chromaticity $\left(C^{*}=\left(a^{* 2}+b^{* 2}\right)^{1 / 2}\right.$, quantity of colour $)$ and hue angle $\left(H^{*}=\operatorname{tang}^{-1}\left(b^{*} / a^{*}\right)\right.$, real colour) were calculated as described by Wyszecki and Stiles (1982). Intramuscular fat was determined with $20.0 \mathrm{~g}$ (in duplicate) of minced meat in a Soxhlet apparatus using petroleum ether (NP-1224, 1982). The pigment concentration in muscle samples was analysed according to Boccard et al. (1981). Total collagen was determined, after acid hydrolysis, by spectrophotometric assay of L-hydroxyproline (AOAC, 1990). The amount of L-hydroxyproline in the supernatant and residue fractions was converted into soluble and insoluble collagen using 7.25 and 7.52 as factors (Cross et al., 1973). Collagen was expressed as total (soluble + insoluble) and soluble collagen as the percentage of the total. Cooking loss was evaluated in refrigerated meat samples of similar geometry, individually placed inside polyethylene bags in a water bath at $75^{\circ} \mathrm{C}$. Samples were heated until an internal temperature of $70{ }^{\circ} \mathrm{C}$ (monitored with thermocouples introduced in the core) and cooled for $15 \mathrm{~min}$ under running tap water. They were taken from the bags, dried with filter paper and weighed. Cooking loss was expressed as the percentage of loss related to the initial weight. After measurement of cooking loss, samples were stored in a refrigerator and used for objective tenderness determinations (after equilibration at room temperature). The Warner-Bratzler shear force (WBSF) was measured in sub-samples (at least 3 ) of $1 \mathrm{~cm}^{2}$ cross section and $3-4 \mathrm{~cm}$ in length with fibres perpendicular to the direction of the blade attached to a Stevens QTS 25 apparatus.

\subsection{Statistical analysis}

A PC and DA analysis was performed using the Princomp procedure from the SAS (1999) package and the SPSS V. 12.1 package (SPSS Inc., Chicago, USA), respectively.

\section{Results and discussion}

Tables 1 and 2 show means, standard deviations and coefficients of variation of the carcass and the meat quality measurements. The coefficient of variation of some variables, such as dressing percentage, muscle and bone content, $\mathrm{pH}, L^{*}, C^{*}$, and dry matter was lower than $10 \%$, while for some others, like refrigerated losses, subcutaneous:muscle ratio, intramuscular fat, total pigment and total collagen, was higher than $30 \%$. Tables 3 and 4 display the correlation coefficients $(r)$ between the variables used for carcass quality and meat quality, respectively. There are significant correlations between subcutaneous fat and carcass measurements indices, for example: $\mathrm{CC}(r=0.46, P<0.001), \mathrm{B} / \mathrm{Lg}$ $(r=0.35, P<0.01), \operatorname{LgC}(r=0.43, P<0.001)$, all of them positive. The positive correlation between carcass compactness and subcutaneous fat proportion agreed with results of Marichal et al. (2003) with kid goats used to compare carcass and meat quality at 6,10 and $25 \mathrm{~kg}$ of slaughter live weight.

The highest correlation coefficient is between hot carcass weight and carcass compactness $(r=0.96$, $P<0.001$ ), however the correlation coefficients of the others than can be mentioned are between leg

Table 6

Results from the principal component analysis for the first five principal components of the meat quality measurements

\begin{tabular}{llll}
\hline Component & Eigenvalue & $\begin{array}{l}\text { Portion of variance } \\
(\%)\end{array}$ & $\begin{array}{l}\text { Cumulative variance } \\
(\%)\end{array}$ \\
\hline 1 & 4.99 & 31.2 & 31.2 \\
2 & 2.65 & 16.6 & 47.8 \\
3 & 1.68 & 10.5 & 58.3 \\
4 & 1.44 & 9.0 & 67.3 \\
5 & 1.23 & 7.7 & 75.0 \\
\hline
\end{tabular}




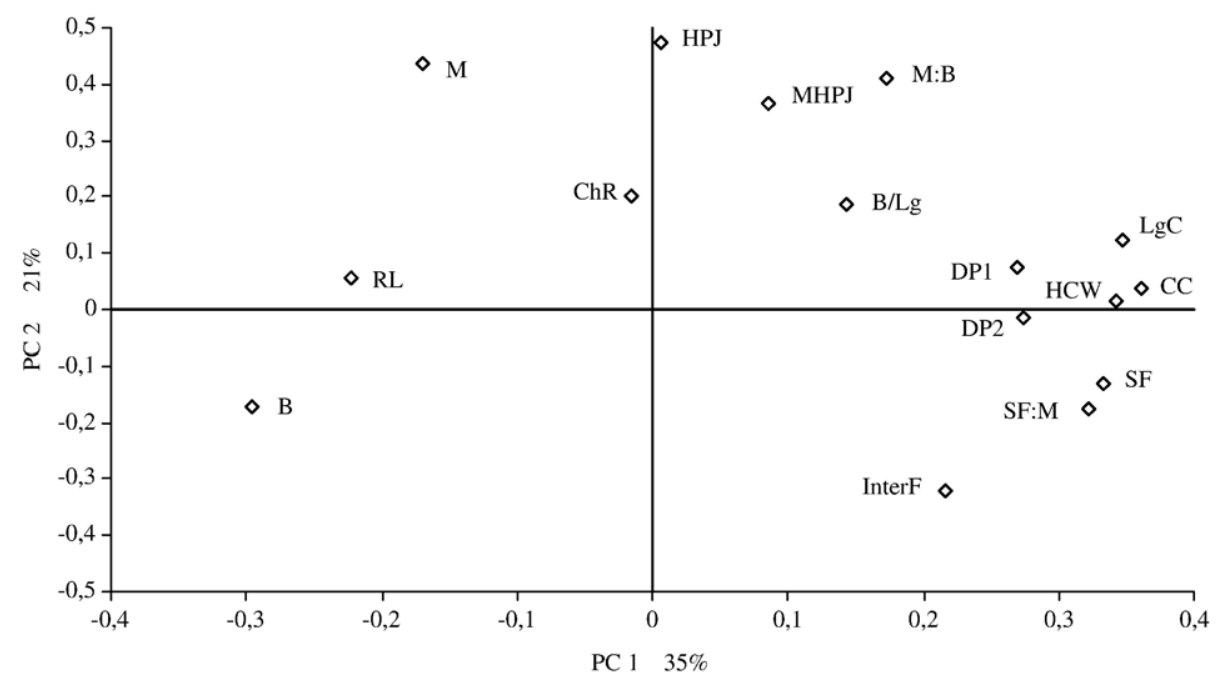

Fig. 1. Projection of the carcass quality measurements in the plane defined by the first two principal components (PCs). Abbreviations: HCW, hot carcass weight; DP1, dressing percentage1; DP2, dressing percentage2; RL, refrigerated losses; CC, carcass compactness index; B/Lg, buttock/leg index; ChR, chest roundness index; $\mathrm{LgC}$, leg compactness index; HPJ, higher priced joints; MHPJ, muscle higher priced joints; M, muscle; SF, subcutaneous fat; InterF, intermuscular fat; B, bone; M:B, muscle:bone ratio; SF:M, subcutaneous:muscle ratio.

compactness and carcass compactness $(r=0.93$, $P<0.001)$, between leg compactness and hot carcass weight $(r=0.93, P<0.001)$.

In relation to the meat quality traits it could be remarked the correlations between the colour parameters, for example, $r$ for redness and chromaticity $(r=0.98$, $P<0.001)$, yellowness and hue $(r=0.89, P<0.001)$, lightness and hue $(r=0.88, P<0.001)$, redness and pigment content $(r=0.80, P<0.001)$, all of them positive.
Negative correlation coefficients were found between lightness and redness $(r=-0.88, P<0.001)$, lightness and pigment content $(r=-0.85, P<0.001)$, lightness and chromaticity $(r=-0.80, P<0.001)$ and lightness and yellowness $(r=-0.68, P<0.001)$ and between ultimate $\mathrm{pH}$ and cooking losses $(r=-0.51, P<0.001)$. Significant positive correlations between muscle pigment concentration and muscle redness and chroma have previously been reported by Dhanda et al. (2003). In the same study a

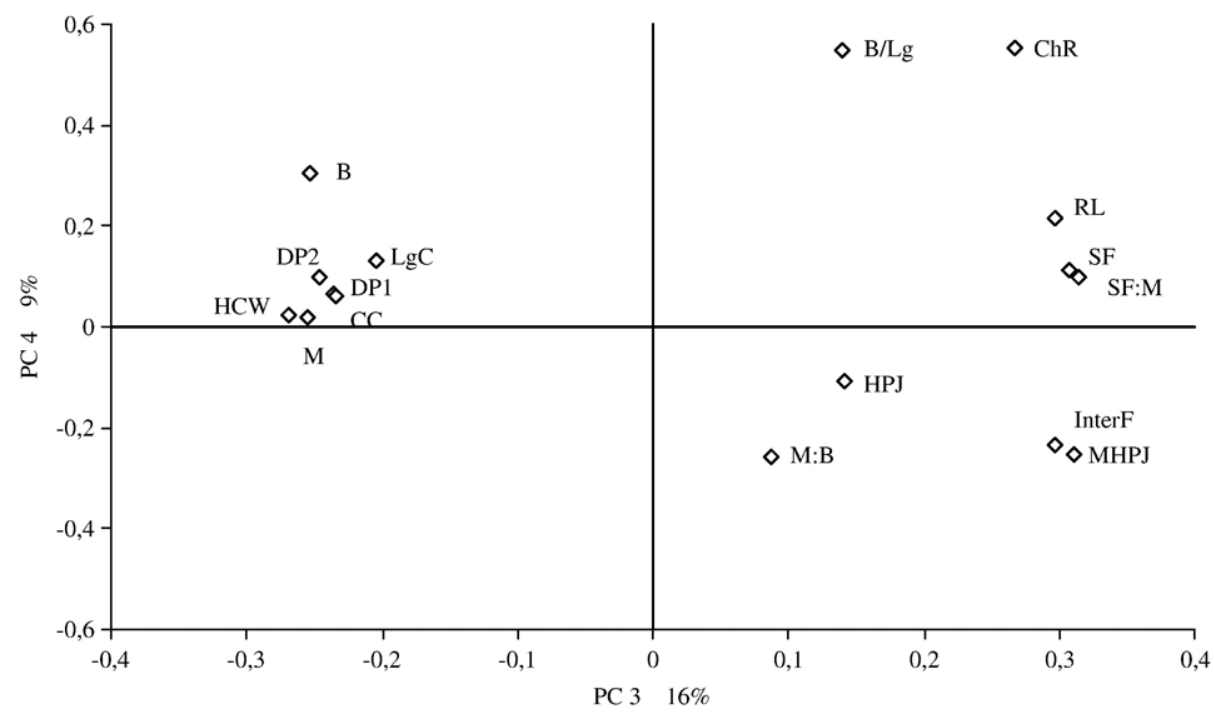

Fig. 2. Projection of the carcass quality measurements in the plane defined by the third and fourth principal components (PCs). Abbreviations: The abbreviations are the same as in Fig. 1 . 


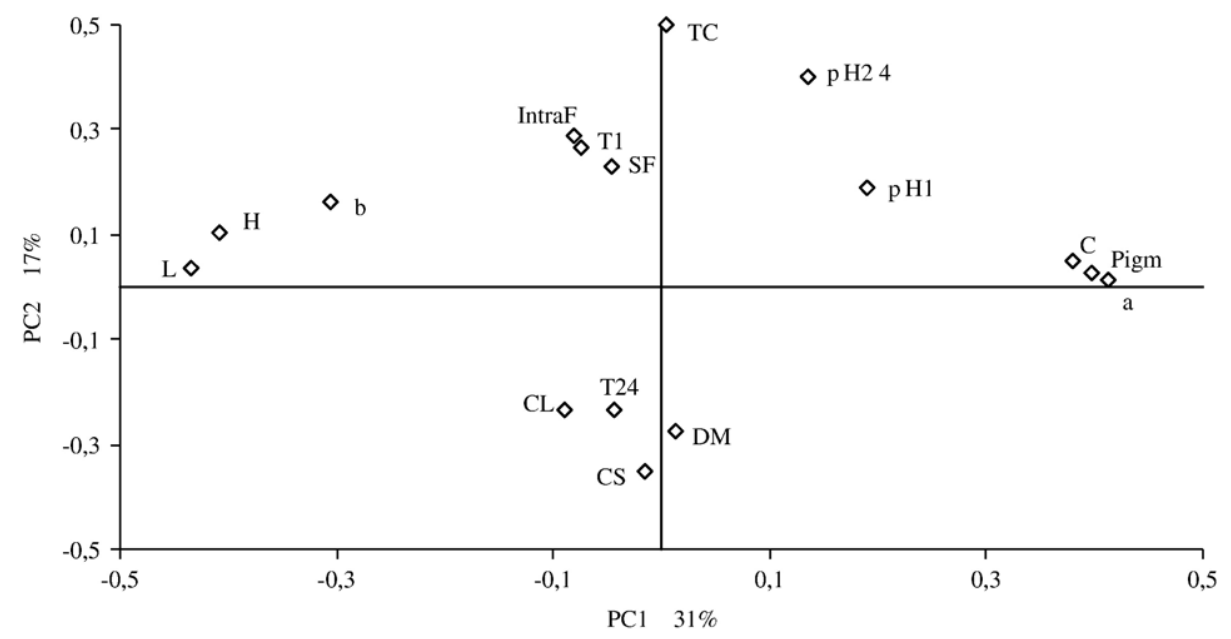

Fig. 3. Projection of the meat quality measurements in the plane defined by the first two principal components (PCs). Abbreviations: pH1, pH measured at $1 \mathrm{~h}$ after slaughter; $\mathrm{pH} 24, \mathrm{pH}$ measured at $24 \mathrm{~h}$ after slaughter; T1, temperature measured $1 \mathrm{~h}$ after slaughter; T24, temperature measured $24 \mathrm{~h}$ after slaughter; $L^{*}, a^{*}, b^{*}$, chroma-meter values; $C^{*}$, chromaticity; $H^{*}$, hue; DM, dry matter; IntraF, Intramuscular fat; CL, cooking loss; SF, shear force; Pigm, total pigment; CS, collagen solubility; TC, total collagen.

negative correlation was found between muscle colour lightness and pigment content $(r=-0.58, P<0.01)$. The results of the PC analysis are presented in Table 5 for carcass quality variables and in Table 6 for meat quality variables. The first four PCs explain about $80 \%$ of the total variation for carcass quality measurements $(35 \%$, $21 \%, 16 \%$ and $9 \%$, respectively) and $68 \%$ for the meat quality traits $(31 \%, 17 \%, 11 \%$ and $9 \%$, respectively). In other words, $80 \%$ of the total variance for carcass quality and $68 \%$ of the total variance for meat quality, in the 16 considered variables can be condensed into four new variables (PCs). The results achieved with the PC analysis applied to analyse carcass and meat quality variables of goat kids are similar with the results reported by other analogous studies with other species. In rabbits, Hernández et al. (2000) analysed meat quality using 23 variables, including $\mathrm{pH}$, meat colour, water holding capacity, cooking loss, fatty acid composition and sensory parameters. They found that the first four PCs for meat quality explained $62 \%$ of the total variation. Destefanis et al. (2000) with meat quality measurements (pH, chemical analysis, colour, hydroxyproline content, lightness, hue, drip losses, cooking losses, shear force and sensory variables) in beef showed that $62.5 \%$ of the total variation

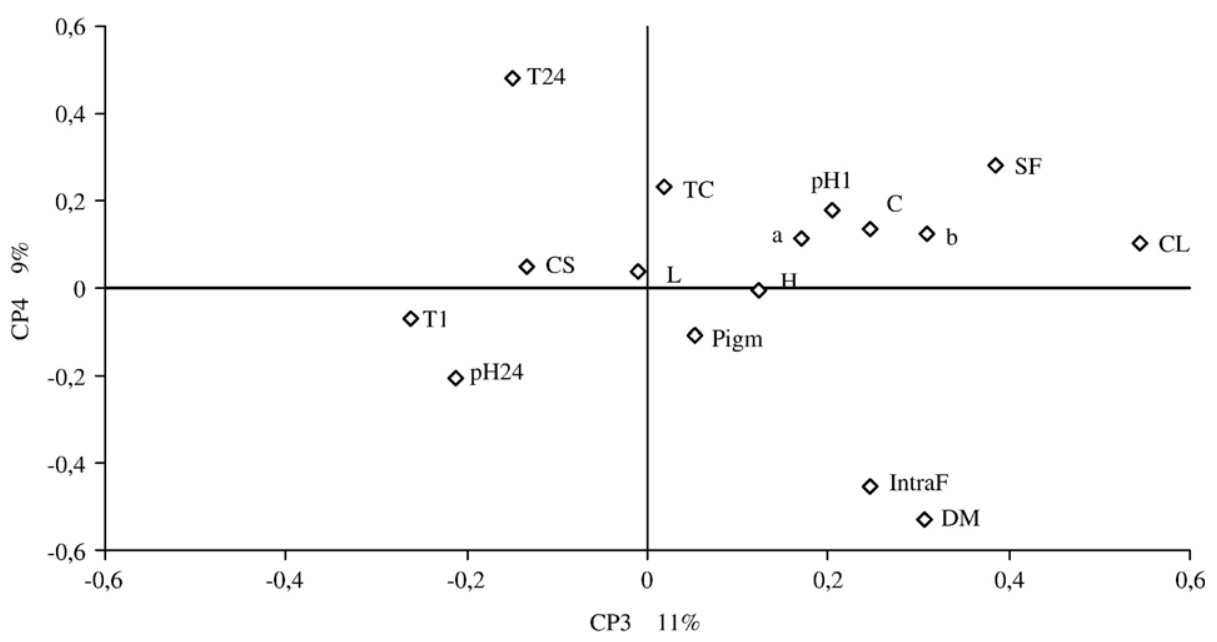

Fig. 4. Projection of the meat quality measurements in the plane defined by the third and fourth principal components (PCs). Abbreviations: The abbreviations are the same as in Fig. 3. 


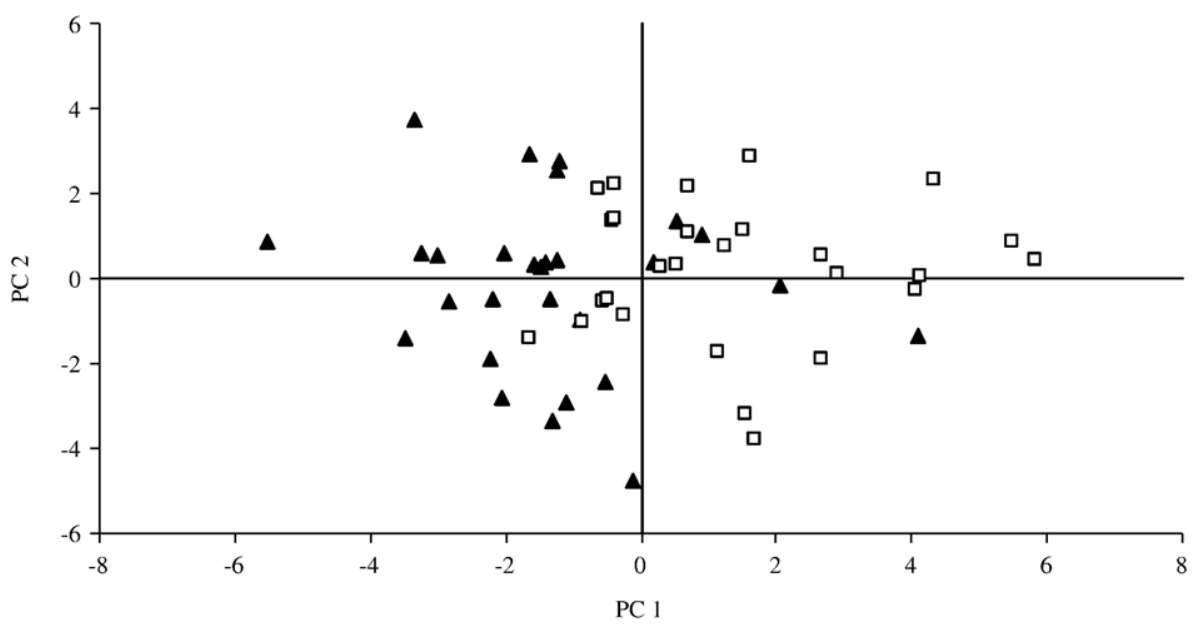

Fig. 5. Projection of the carcass quality data of the two groups of SLW studied in the plane defined by the two principal components (PCs). Symbols: $\boldsymbol{\Delta}$, SLW lower than $10 \mathrm{~kg}$; $\square$, SLW higher than $10 \mathrm{~kg}$.

is explained by the first three components. In lambs, Cañeque et al. (2004) analysed carcass quality and meat quality measurements as separate sets of variables. Their results showed that the first four components explained $72 \%$ of total variation for carcass quality measurements and $50 \%$ for the meat quality measurements.

In the present study, the first PC of the carcass quality parameters is characterized by two measurements of compactness (carcass and leg), carcass weight and subcutaneous fat (Fig. 1). In the loading plot (Fig. 1) these variables are placed far from the origin of the first PC according to their proportion in the new variable. The second PC is characterized by higher priced joints proportion, muscle proportion of the higher priced joints and the carcass and muscle and bone ratio, all of these variables are located on the top in the loading plot (Fig. 1). All variables of carcass quality had similar proportions in the third $\mathrm{PC}$, although muscle and bone ratio had the lowest value and the muscle in higher priced joints showed the highest (Fig. 2). Ultimately, the fourth PC is characterized by two indices of carcass conformations measurements (chest roundness and leg compactness).

Figs. 3 and 4 show plots of measurements of meat quality on the first 4 PCs. The first PC of the meat quality parameters is characterized by colour parameters ( $L^{*}, b^{*}, a^{*}, C^{*}, H^{*}$ and total pigment) located far from the origin, which means that they are important in

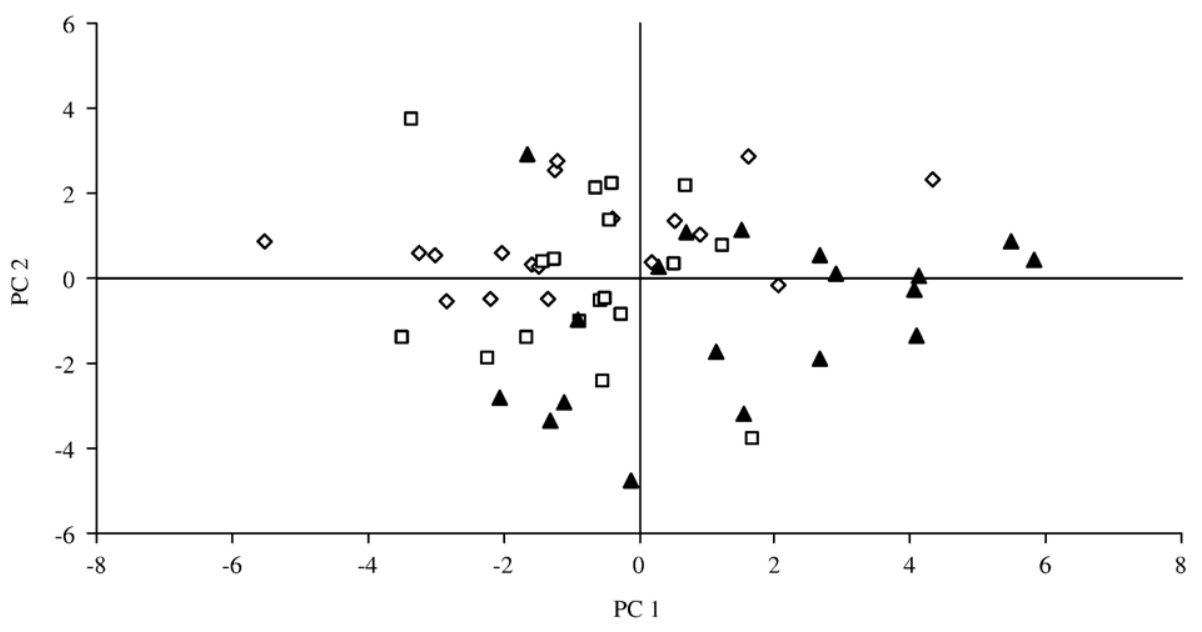

Fig. 6. Projection of the carcass quality data of the three genotypes studied in the plane defined by the two principal components (PCs). Symbols: $\diamond$, Bravia; $\square, \mathrm{B} \times \mathrm{S} ; \boldsymbol{\Delta}$, Serrana. 


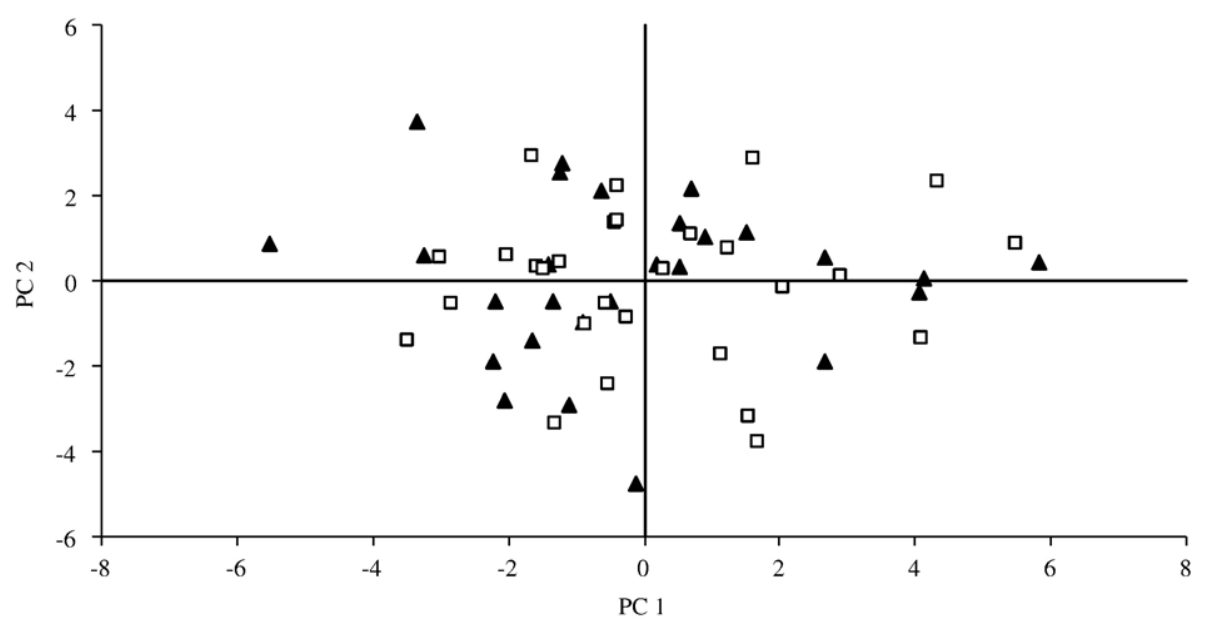

Fig. 7. Projection of the carcass quality data of the two sexes studied in the plane defined by the two principal components (PCs). Symbols: $\mathbf{\Delta}$, female; $\square$, male.

explaining the observed variation (Fig. 3). Colour traits close to each other are positively correlated, whereas if they are separated by $180^{\circ}$, are negatively correlated. Collagen determinations (total collagen and collagen solubility) are located on the second PC in opposition, expressing a negative correlation. In Fig. 4, cooking loss had high importance defining the third PC, whereas dry matter, temperature measured at $24 \mathrm{~h}$ and intramuscular fat content are important in explaining the observed variation in the fourth PC. Fig. 5 shows the projection of the carcass quality data in the first two PCs. Two separate groups can be observed. Kids with a slaughter live weight lower than $10 \mathrm{~kg}$, located on the left side of the figure, where the bone and muscle proportion of the carcass and refrigerated losses lay. Marichal et al. (2003) found that kids with $6 \mathrm{~kg}$ of slaughter live weight had greater refrigerated losses and bone content than kids with 10 and $25 \mathrm{~kg}$ of slaughter live weight. Velasco et al. (2000) observed that increased slaughter weight in Talaverana suckling lambs resulted in a lower proportion of muscle and bone while subcutaneous and intermuscular fat increased. In the present study the kids with slaughter live weight higher than $10 \mathrm{~kg}$ lie on the right side of the figure, where the fatness and carcass conformation traits lay. These relationships among carcass conformation and fatness are in agreement with Marichal et al. (2003) who reported that carcasses with high carcass compactness index present more

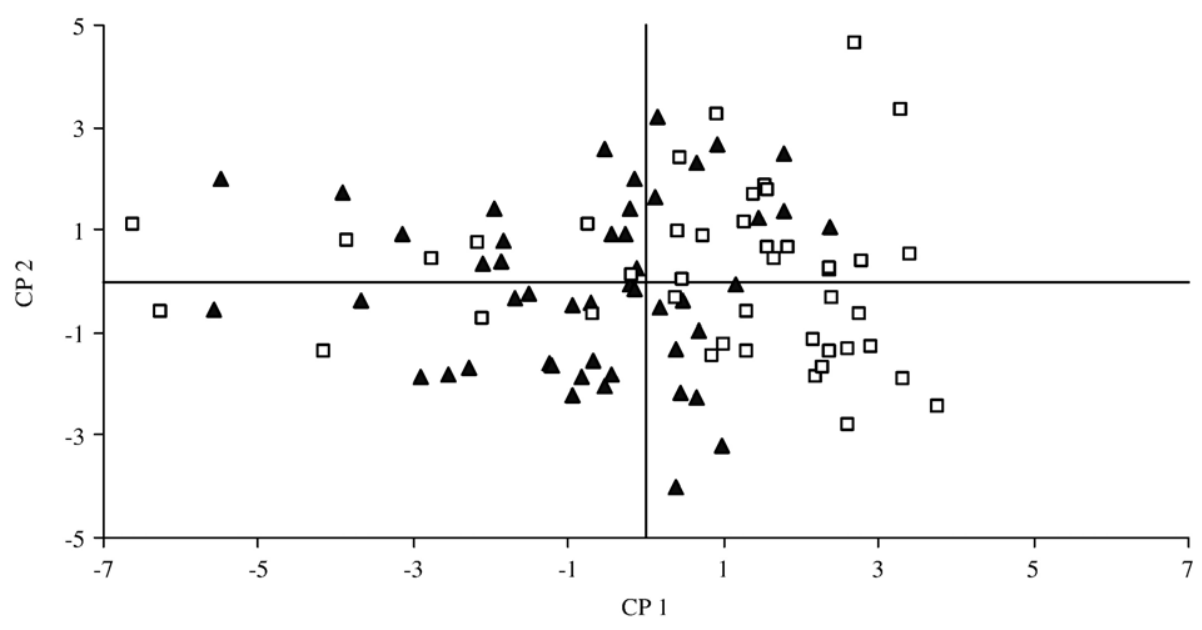

Fig. 8. Projection of the meat quality data of the two groups of SLW studied in the plane defined by the two principal components (PCs). Symbols: $\mathbf{\Delta}$, SLW lower than $10 \mathrm{~kg} ; \square$, SLW higher than $10 \mathrm{~kg}$. 


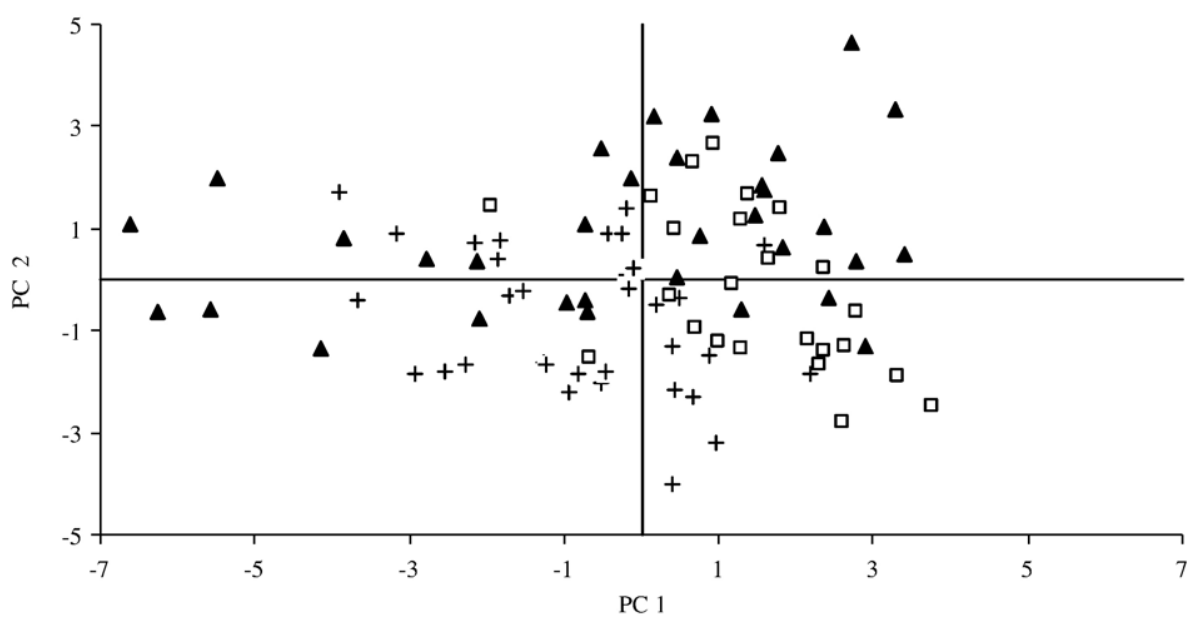

Fig. 9. Projection of the meat quality data of the three genotypes studied in the plane defined by the two principal components (PCs). Symbols: + , Bravia; $\square, \mathrm{B} \times \mathrm{S} ; \boldsymbol{\Lambda}$, Serrana.

subcutaneous fat, lower bone content and better muscle/ bone ratio.

Fig. 6 shows the projection of the carcass quality data of the three genotypes studied $(B, B \times S, S)$ in the plane defined by the first two PCs. Serrana genotype is preferentially located along the right side of graph where kids with SLW higher than $10 \mathrm{~kg}$ lie, however this group displays some variability, because some $\mathrm{S}$ kids are placed to the left in the score plot (Fig. 6).

Fig. 7 displays the distribution of the carcass quality data of the two genders studied in the plane defined by the first two PCs. No defined sets of points are created with respect to carcass quality of the two groups. Fig. 8 shows the projection of the meat quality data in the first two PCs. Kids with a SLW higher than $10 \mathrm{~kg}$ are preferentially located along the right side of the graph, where the colour parameters $a^{*}, C^{*}$ and pigment content are placed. Kids with a SLW lower than $10 \mathrm{~kg}$ are preferentially located along the left side of the graph, where the colour parameters $L^{*}, H$ and $b^{*}$ traits are placed. These results show that muscle colour became darker and more red with increasing age or slaughter live weight. Fig. 9 displays the distribution of the meat quality data of the three genotypes in the first two PCs. Two separate groups can be observed. Kids of $\mathrm{S} \times \mathrm{B}$ genotype are located on the right side of the graph where the colour parameters $a^{*}, C^{*}$ and pigment content are placed and kids of B genotype, are located preferentially on the left side of the figure, where the colour parameters $L^{*}, H^{*}$ and $b^{*}$ traits are placed. Serrana genotype shows high

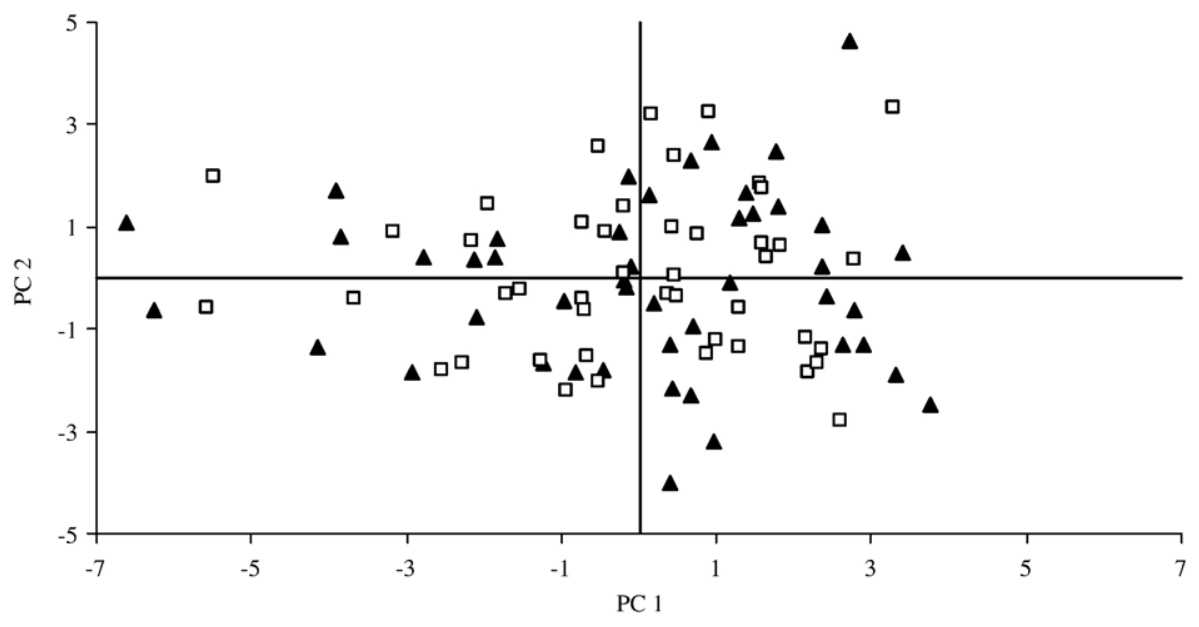

Fig. 10. Projection of the meat quality data of the two sexes studied in the plane defined by the two principal components (PCs). Symbols: $\mathbf{\Delta}$, female; $\square$, male. 


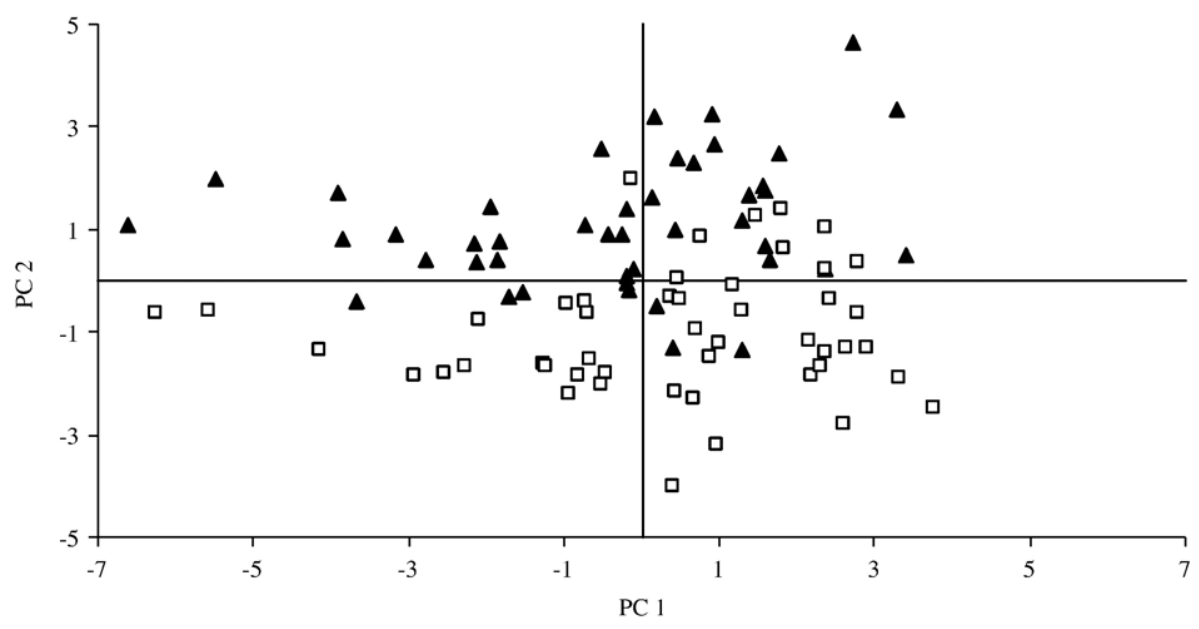

Fig. 11. Projection of the meat quality data of the two muscles studied in the plane defined by the two principal components (PCs). Symbols: $\mathbf{\Delta}$, GB; $\square$, LTL.

variability. Significant differences between goat genetic groups in meat colour (CIE $L^{*}, a^{*}, b^{*}$ values) had been reported by Dhanda et al. (1999b).

Fig. 10 displays the distribution of the meat quality data of the two sexes studied in the plane defined by the first two PCs. As for carcass quality, no defined sets of points are created with respect to meat quality of male and female kids. The differences between sexes in meat quality of lambs are not in general, very important (Sañudo et al., 1998). Similarly, in the studies conducted by Todaro et al. (2004) with goat kids meat colour, shear force values and chemical composition were unaffected by sex. Fig. 11 displays the distribution of the meat quality data of the two muscles studied in the plane defined by the first two PCs. GB muscle is located on the top in the projection plot, where total collagen $(\%$ $\mathrm{DM})$, ultimate $\mathrm{pH}$, intramuscular fat content and shear force are placed. LTL muscle is located on the bottom in the projection plot, where collagen solubility (\%total), dry matter and cooking loss are placed. It is recognized that considerable differences with respect to composition and quality exist among the muscles (Sañudo et al., 1998). Histochemical and biochemical properties of a muscle, such as fibre type, oxidative and glycolytic capacity, and lipid contents, are factors that may have an influence on meat quality (Karlsson et al., 1999). For example, variations among muscles in $\mathrm{pH} 24$ might be explained by the fact that muscles differ in red and white fibre type proportions and therefore, they also differ in energy metabolism patterns in both ante- and postmortem (Klont et al., 1998).

Multivariate discriminant analysis was also performed to determine if it is possible to discriminate kids due to slaughter live weight, genotype, sex and type of muscle, on the basis of the carcass quality or the meat quality traits. The results are presented in Table 7 . Results for better equations for live weight identification, on the basis of the carcass quality traits, show good accuracy, as $98.2 \%$ of the original grouped cases were correctly assigned to the live weight they belong to. On the basis of the meat quality traits, $80.4 \%$ of original grouped cases were correctly assigned. Results for better functions for genotype recognition on the basis of the carcass quality showed that $89.1 \%$ of the samples could be correctly assigned to the breed they belong to and on the basis of the meat quality $93.5 \%$ were correctly

Table 7

Classification results from discrimination equations for live weight, genotype, sex and type of muscle

\begin{tabular}{|c|c|c|c|c|c|c|}
\hline \multirow{3}{*}{$\begin{array}{l}\text { Belongs to } \\
\text { Trait }\end{array}$} & \multicolumn{3}{|c|}{ Carcass quality } & \multicolumn{3}{|c|}{ Meat quality } \\
\hline & \multirow{2}{*}{$\begin{array}{l}\text { Total } \\
n\end{array}$} & \multicolumn{2}{|c|}{$\begin{array}{l}\text { Correctly } \\
\text { classified }\end{array}$} & \multirow{2}{*}{$\begin{array}{l}\text { Total } \\
n\end{array}$} & \multicolumn{2}{|c|}{$\begin{array}{l}\text { Correctly } \\
\text { classified }\end{array}$} \\
\hline & & $n$ & $\%$ & & $n$ & $\%$ \\
\hline \multicolumn{7}{|l|}{ Live weight } \\
\hline$\leq 10 \mathrm{~kg}$ & 28 & 27 & 96.4 & 48 & 39 & 81.3 \\
\hline$>10 \mathrm{~kg}$ & 27 & 27 & 100 & 44 & 35 & 79.5 \\
\hline \multicolumn{7}{|l|}{ Genotype } \\
\hline B & 18 & 17 & 94.4 & 34 & 31 & 91.2 \\
\hline $\mathrm{B} \times \mathrm{S}$ & 18 & 17 & 94.4 & 25 & 24 & 96.0 \\
\hline $\mathrm{S}$ & 19 & 15 & 78.9 & 33 & 31 & 93.9 \\
\hline \multicolumn{7}{|l|}{ Sex } \\
\hline Female & 27 & 25 & 92.6 & 47 & 33 & 70.2 \\
\hline Male & 28 & 20 & 71.4 & 45 & 33 & 73.3 \\
\hline \multicolumn{7}{|l|}{ Muscle } \\
\hline GB & - & - & - & 44 & 43 & 97.7 \\
\hline LTL & - & - & - & 48 & 46 & 95.8 \\
\hline
\end{tabular}


identified. The models developed for sex recognition, on the basis of the carcass quality traits, were able to identify almost all female kids ( 25 of 27 ), and to a lesser extent the male kids ( 20 of 28). On the basis of the meat quality traits only 33 of 47 female kids were correctly assigned and 33 of 45 male kids were correctly assigned, resulting in the lowest accuracy among sex type. The models developed for muscle recognition were able to identify almost all samples of GB (43 of 44) and LTL (46 of 48) muscles. The results showed that $96.7 \%$ of original grouped cases were correctly assigned to the muscle they belong to. It can be said that carcass characteristics allow a clear discrimination among slaughter live weight and meat quality traits allow a clear discrimination among muscles.

\section{Conclusions}

The differences between SLW groups in carcass quality show that, despite the narrow weight range of SLW, they were enough to make distinctions between groups with the first PC differentiating with respect to carcass quality between SLW higher or lower than $10 \mathrm{~kg}$. Nevertheless, the differences between SLW groups in meat quality tend to be small, which implies that meat quality among these groups was similar. The first PC differentiates genotypes in two groups with respect to meat quality, especially in relation to meat colour traits while the second PC differentiates LTL and GB muscles.

\section{References}

Albertí, P., Ripoll, G., Goyache, F., Lahoz, F., Olleta, J.L., Panea, B., Sañudo, C., 2005. Carcass characterisation of seven Spanish beef breeds slaughtered at two commercial weights. Meat Sci. 71, 514-521.

AOAC, 1990. Official methods of analysis, 15th ed. Hidroxiprolin in meat and meat products, vol. 1. Association of Official Analytical Chemists, Inc., Virginia.

Boccard, R., Buchter, L., Casteels, E., Cosentino, E., Dransfield, E., Hood, D.E., Joseph, R.L., MacDougall, D.B., Rhodes, D.N., Schön, I., Tinbergen, B.C., Touraille, C., 1981. Procedures for measuring meat quality characteristics in beef production experiments. Report of a working group in the Commission of the European Communities' (CEC) beef production research programme. Livest. Prod. Sci. 8, 385-397.

Brito, G., Andrade, J.M., Havel, J., Díaz, C., García, F.J., PeñaMéndez, E.M., 2006. Classification of some heat-treated liver pastes according to container type, using heavy metals content and manufacturer's data, by principal components analysis and potential curves. Meat Sci. 74, 296-302.

Cameron, M.R., Luo, J., Sahlu, T., Hart, S.P., Coleman, S.W., Goetsch, A.L., 2001. Growth and slaughter traits of Boer $\times$ Spanish, Boer $\times$ Angora, and Spanish goats consuming a concentrate-based diet. J. Anim. Sci. 79, 1423-1430.
Cañeque, V., Perez, C., Velasco, S., Díaz, M.T., Lauzurica, S., Álvarez, I., Ruiz de Huidobro, F., Onega, E., De la Fuente, J., 2004. Carcass and meat quality of light lambs using principal component analysis. Meat Sci. 67, 595-605.

Colomer-Rocher, F., Morand-Fehr, P., Kirton, A.H., 1987. Standard methods and procedures for goat carcass evaluation, jointing and tissue separation. Livest. Prod. Sci. 17, 149-159.

Cross, H.R., Carpenter, Z.L., Smith, G.C., 1973. Effects of intramuscular collagen and elastin on bovine muscle tenderness. J. Food Sci. 38, 998-1003.

Destefanis, G., Barge, M.T., Brugiapaglia, A., Tassone, S., 2000. The use of principal component analysis (PCA) to characterize beef. Meat Sci. 56, 255-259.

Dhanda, J.S., Taylor, D.G., McCosker, J.E., Murray, P.J., 1999a. The influence of goat genotype on the production of Capretto and Chevon carcasses. 1. Growth and carcass characteristics. Meat Sci. $52,355-361$.

Dhanda, J.S., Taylor, D.G., Murray, P.J., McCosker, J.E., 1999b. The influence of goat genotype on the production of Capretto and Chevon carcasses. 2. Meat quality. Meat Sci. 52, 363-367.

Dhanda, J.S., Taylor, D.G., Murray, P.J., 2003. Part 1. Growth, carcass and meat quality parameters of male goats: effects of genotype and liveweight at slaughter. Small Rumin. Res. 50, 57-66.

Fisher, A.V., de Boer, H., 1994. The EAAP standard method of sheep carcass assessment and dissection procedures. Livest. Prod. Sci. $38,149-159$.

Hernández, P., Pla, M., Blasco, A., 1997. Relationships of meat characteristics of two lines of rabbits selected for litter size and growth rate. J. Anim. Sci. 75, 2936-2941.

Hernández, P., Pla, M., Blasco, A., 1998. Carcass characteristics and meat quality of rabbit lines selected for different objectives: II. Relationships between meat characteristics. Livest. Prod. Sci. 54, 125-131.

Hernández, P., Pla, M., Oliver, M.A., Blasco, A., 2000. Relationships between meat quality measurements in rabbits fed with three diets of different fat types and content. Meat Sci. 55, 379-384.

Hogg, B.W., Mercer, G.J.K., Mortimer, B.J., Kirton, A.H., Duganzich, D.M., 1992. Carcass and meat quality attributes of commercial goats in New Zealand. Small Rumin. Res. 8, 243-256.

Johnson, D.D., McGowan, C.H., 1998. Diet/management effects on carcass attributes and meat quality of young goats. Small Rumin. Res. 28, 93-98.

Kadim, T., Mahgoub, O., Al-Ajmi, D.S., Al-Maqbaly, R.S., Al-Saqri, N.M., Ritchie, A., 2003. An evaluation of the growth, carcass and meat quality characteristics of Omani goat breeds. Meat Sci. 66, 203-210.

Karlsson, A., 1992. The use of principal component analysis (PCA) for evaluation results from pig meat quality measurements. Meat Sci. 31, 423-433.

Karlsson, A.H., Klont, R.E., Fernandez, X., 1999. Skeletal muscle fibres as factors for pork quality. Livest. Prod. Sci. 60, 255-269.

Klont, R.E., Brocks, L., Eikelenboom, G., 1998. Muscle fibre type and meat quality. Meat Sci. 49, S219-S229.

Laville, E., Martin, V., Bastien, O., 1996. Prediction of composition traits of young Charolais bull carcasses using a morphometric method. Meat Sci. 44, 93-104.

Marichal, A., Castro, N., Capote, J., Zamorano, M.J., Argüello, A., 2003. Effects of live weight at slaughter $(6,10$ and $25 \mathrm{~kg})$ on kid carcass and meat quality. Livest. Prod. Sci. 83, 247-256.

Marinova, P., Banskalieva, V., Alexandrov, S., Tzvetkova, V., Stanchev, H., 2001. Carcass composition and meat quality of kids fed sunflower oil supplemented diet. Small Rumin. Res. 42, 219-227. 
Moreno, T., Varela, A., Oliete, B., Carballo, J.A., Sánchez, L., Montserrat, L., 2006. Nutritional characteristics of veal from weaned and unweaned calves: discriminatory ability of the fat profile. Meat Sci. 73, 209-217.

Næs, T., Baardseth, P., Helgesen, H., Isaksson, T., 1996. Multivariate techniques in the analysis of meat quality. Meat Sci. 43, S135-S149.

NP-1224, 1982. Carnes, derivados e produtos cárneos. Determinação do teor de matéria gorda livre. Instituto Português da Qualidade, Lisboa.

Oliete, B., Carballo, J.A., Varela, A., Moreno, T., Monserrat, L., Sánchez, L., 2006. Effect of weaning status and storage time under vacuum upon physical characteristics of meat of the Rubia Gallega breed. Meat Sci. 73, 102-108.

Oman, J.S., Waldron, D.F., Griffin, D.B., Savell, J.W., 2000. Carcass traits and retail display-life of chops from different goat breed types. J. Anim. Sci. 78, 1262-1266.

Santos-Silva, J., Mendes, I.A., Bessa, R.J.B., 2002. The effect of genotype, feeding system and slaughter weight on the quality of light lambs 1. Growth, carcass composition and meat quality. Livest. Prod. Sci. 76, 17-25.
Sañudo, C., Sanchez, A., Alfonso, M., 1998. Small ruminant production systems and factors affecting lamb meat quality. Meat Sci. 49, S29-S64.

SAS, 1999. SAS User's Guide Statistics, Third edition. SAS Institute Inc., Cary, NC. Version 8.

Sen, A.R., Santra, A., Karim, S.A., 2004. Carcass yield, composition and meat quality attributes of sheep and goat under semiarid conditions. Meat Sci. 66, 757-763.

Todaro, M., Corrao, A., Alicara, M.L., Schinelli, R., Giaccone, P., Priolo, A., 2004. Effects of litter size and sex on meat quality traits of kid meat. Small Rumin. Res. 54, 191-196.

Velasco, S., Lauzurica, S., Cañeque, V., Pérez, C., Huidobro, F., Manzanares, C., Díaz, M.T., 2000. Carcass and meat quality of Talaverana breed suckling lambs in relation to gender and slaughter weight. Anim. Sci. 70, 253-263.

Webb, E.C., Casey, N.H., Simela, L., 2005. Goat meat quality. Small Rumin. Res. 60, 153-166.

Wyszecki, G., Stiles, W.S., 1982. Colorimetry. Color science. Concepts and Methods, Quantitative Data and Formulae. Wiley, New York, pp. 117-248 